\title{
Cryptococcosis in AIDS
}

\author{
P Imwidthaya, N Poungvarin
}

\begin{abstract}
Summary
A total of 87 patients (17 female, 70 male) were admitted to Siriraj Hospital, Mahidol University, Bangkok, Thailand, from January 1996 to December 1997, with a diagnosis of cryptococcal meningitis and underlying AIDS. The age range was 14-70 years, mean 32.1. Six females $(35 \%)$ and thirty-one males (44\%) died, while the others were discharged home after clinical improvement. The mean duration of admission of those who died was 14.5 days, which was shorter than that of the patients who survived (25.7 days). Cerebral cryptococcosis was diagnosed using culture $(100 \%)$, India ink preparation (91\%), latex agglutination test $(100 \%)$, and polymerase chain reaction $(86 \%)$. Polymerase chain reaction fingerprinting of Cryptococcus neoformans revealed $99 \%$ serotype $A$ and $1 \%$ serotype $B$. The mean minimum inhibitory concentrations of amphotericin $B$, flucytosine, fluconazole and itraconazole against 87 isolates of $C$ neoformans were $0.55 \mu \mathrm{g} / \mathrm{ml}(0.25-1, \mathrm{SD}=0.22), 9.5$ $\mu \mathrm{g} / \mathrm{ml}(2-20, \mathrm{SD}=4.91), 6.9 \mu \mathrm{g} / \mathrm{ml}(1-16$, $\mathrm{SD}=4.42)$ and $0.36 \mu \mathrm{g} / \mathrm{ml}(0.125-1.0, \mathrm{SD}=$ $0.23)$, respectively. These findings showed that the cryptococcal infections were sensitive to these antifungal agents.
\end{abstract}

Keywords : Cryptococcus neoformans; AIDS; polymerase chain reaction fingerprinting; antifungal agents

Fungal infections are an important problem in medicine nowadays. The rate of fungal infection in Thailand is increasing, not only because of environmental factors that support the growth of several fungi, but also because there are an increasing number of immunocompromised patients, particularly those with AIDS. Cryptococcus neoformans, the organism causing cryptococcosis, was first reported to be pathogenic to man in 1894 and was isolated from pigeon manure in $1955 .{ }^{1}$ The first reported case of cryptococcosis in Thailand was recorded in $1960 .^{2}$ This pathogenic organism is known as an encapsulated yeast and has a worldwide distribution. Among AIDS patients in Thailand, cryptococcosis is the second most common opportunistic infection after tuberculosis and most patients have primary systemic fungal infections and late HIV disease.

The identification of this fungus is based on its morphological and physiological characteristics. Polymerase chain reaction (PCR) with specific primers has been introduced for diagnosing cryptococcosis. ${ }^{3}$ Moreover, two genetically distinct varieties of $C$ neoformans are recognised: $C$ neoformans var neoformans and $C$ neoformans var gattii. ${ }^{4}$ The varieties can be distinguished by their differences in growth on diagnostic media ${ }^{5}$ and by testing with monoclonal antibodies specific for each type. ${ }^{6}$ Recently, PCR fingerprinting has been introduced ${ }^{7}$; this method has been reported as being stable. ${ }^{8}$ The purpose of this study was to investigate the presentation, underlying diseases, outcome of infected patients, serotype and drug susceptibility of $C$ neoformans isolated from patients admitted to Siriraj Hospital, Mahidol University, Bangkok, Thailand, from January 1996 to December 1997. Furthermore, we wished to compare conventional and PCR methods for diagnosing cryptococcosis.

\section{Materials and methods}

SPECIMENS

A total of 87 isolates of $C$ neoformans were cultured from the cerebrospinal fluid (CSF) of 17 female and 70 male patients admitted to Siriraj Hospital between January 1996 and December 1997. The culture medium used was Sabouraud dextrose agar (SDA) without cycloheximide. Identification of $C$ neoformans was based on India ink preparation, growth in culture at $37^{\circ} \mathrm{C}$, a positive urease test, and a positive phenoloxidase test.

\section{LATEX AGGLUTINATION TEST}

A slide latex agglutination test for cryptococcal antigen with titres for each specimen was performed using a locally made LA-kit (Center for Immunodiagnostic Production, Mahidol University). This preparation was polystyrene latex particles coated with $C$ neoformans antibody. The specimens were first inactivated at $56^{\circ} \mathrm{C}$ for $30 \mathrm{~min}$, and then tested with anticryptococcal globulin latex reagent in the presence of glycine buffer, and rotated for 5 minutes at room temperature. The titre was determined by two-fold serial dilution.

PREPARATION OF DNA FROM CLINICAL SPECIMENS A 1-ml sample of CSF was centrifuged at 12 $000 \mathrm{rpm}$ for $5 \mathrm{~min}$ to collect cells; the pellet was then resuspended in $0.5 \mathrm{ml}$ of TE buffer (10 $\mathrm{mM}$ Tris, $1 \mathrm{mM}$ EDTA, $\mathrm{pH}$ 8.0). The cell suspension was transferred to a $1.5 \mathrm{ml}$ microcentrifuge tube which contained $0.5 \mathrm{ml}$ of sterile siliconised glass beads ( $\phi$ 425-600 $\mu \mathrm{m}$; Sigma, USA). The cells were broken by vortexing on the mixer for $1 \mathrm{~min}$ and alternately placing on ice for $1 \mathrm{~min}$. The procedure was repeated 10 times. Then the mixture was heated in a boiling water bath for $10 \mathrm{~min}$. The mixture was centri- 
fuged at $12000 \mathrm{rpm}$ for $5 \mathrm{~min}$ and the supernatant was removed to a new tube. DNA in the supernatant was precipitated as previously described by Bowman ${ }^{9}$, resuspended in $10 \mu \mathrm{l}$ of TE $(10: 1)$ and stored at $-20^{\circ} \mathrm{C}$ until used.

PCR PRIMERS FOR $C$ neoformans

The forward primer was CPL1 (5'GGAGGTAGTGACAATAAATA-3', nucleotide 459-478) and the reverse primer CPR 4 (5'-TGCTAATGTATTCGGGCGATT-3', nucleotide 801-781). These primers were expected to amplify a fragment of $343 \mathrm{bp}$ within the $18 \mathrm{~S}$ rDNA of $C$ neoformans. ${ }^{3}$ The primers were synthesised by the Bio-Service Unit, Mahidol University.

DNA AMPLIFICATION

The polymerase chain reaction was carried out in $600 \mu \mathrm{l}$ microcentrifuge tube (Robbin, USA)

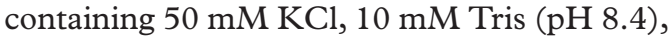
$2.5 \mathrm{mM} \mathrm{MgCl}, 0.01 \%$ gelatin, $25 \mathrm{pmol}$ of each primer, $200 \mu \mathrm{mol}$ of each deoxynucleotide triphosphate and 1 unit of Taq polymerase (BRL, USA). PCR was performed in a DNA thermal cycler (Perkin-Elmer Cetus 480, USA) with denaturation at $94^{\circ} \mathrm{C}$ for $5 \mathrm{~min}$, followed by 50 cycles of denaturation at $94^{\circ} \mathrm{C}$ for $45 \mathrm{~s}$, annealing at $62^{\circ} \mathrm{C}$ for $45 \mathrm{~s}$ and extension at $72^{\circ} \mathrm{C}$ for $45 \mathrm{~s}$. There was one reagent control, one negative control and two positive control tubes included in each set of PCR. The amplification results were analysed only when all the controls produced the correct results.

AGAROSE GEL ELECTROPHORESIS

Samples of $6 \mu$ from each PCR reaction tube were electrophoresed in 4\% Nusieve-agarose (FMC, Germany) and the amplified DNA band was stained with ethidium bromide. Analysis of the amplification was accomplished by taking photographs of gels on a UVtransilluminator (Spectroline ${ }^{\circledR}$ TVC-312 A, USA) with a Polaroid camera (Fotodyne, USA) and then taking note of negative and positive DNA bands in each well.

DNA ISOLATION FOR PCR FINGERPRINTING

DNA was isolated by the physical rupture technique which used glass beads to break cells for isolation of DNA. This method was performed in $1.5-\mathrm{ml}$ microcentrifuge tubes. Yeast cells from SDA were scraped and resuspended into $500 \mu \mathrm{l}$ of TE buffer $(10 \mathrm{mM}$ Tris- $\mathrm{HCl} \mathrm{pH}$ 7.5, $1 \mathrm{mM}$ EDTA). Cells were washed once with $500 \mu \mathrm{l}$ of TE buffer and centrifuged at $12000 \mathrm{rpm}$ for $2 \mathrm{~min}$. The pellet was resuspended in $500 \mu \mathrm{l}$ of TE buffer and the suspension was transferred to a new microcentrifuge tube containing $0.5 \mathrm{ml}$ of glass beads $(\phi$ 425-600 $\mu \mathrm{m}$; Sigma, USA). Cells were broken by vortexing the tube for $1 \mathrm{~min}$ and immediately placing it on ice for $1 \mathrm{~min}$. This step was repeated five times. To the suspension was added $1 / 3$ volume of lysis buffer $(50 \mathrm{mM}$ Tris$\mathrm{HCl} \mathrm{pH} \quad 7.2, \quad 50 \mathrm{mM}$ EDTA, $1 \%$ $\beta$-mercaptoethanol and $3 \%$ sodium dodecyl sulfate) and it was mixed by inversion. The mixture was incubated at $65^{\circ} \mathrm{C}$ for $1 \mathrm{~h}$ and then centrifuged at $12000 \mathrm{rpm}$ for $2 \mathrm{~min}$. The supernatant was transferred to a new microcentrifuge tube, and extracted once with phenol, once with phenol:chloroform:isoamyl alcohol (25:24:1), and finally with chloroform:isoamyl alcohol. DNA was precipitated with ethanol, washed with $70 \%$ ethanol, dried and resuspended in $50 \mu \mathrm{l}$ of TE buffer. Finally, $5 \mu \mathrm{l}$ of ribonuclease $\mathrm{A}$ was added and the DNA incubated at $37^{\circ} \mathrm{C}$ for $1 \mathrm{~h}$. The purified DNA was stored at $-20^{\circ} \mathrm{C}$.

PRIMERS FOR PCR FINGERPRINTING

The phage M13 core sequence 5'GAGGGTGGXGGXTCT-3' was used for PCR to amplify hypervariable and repetitive sequences of $C$ neoformans. ${ }^{7}$ The primer was synthesised by Bio-Service Unit, Mahidol University.

PCR FINGERPRINTING

PCR fingerprinting was established by using prototype strains of $C$ neoformans serotypes A, $\mathrm{B}, \mathrm{C}$, and D. The PCR fingerprinting procedure was performed in $0.6-\mathrm{ml}$ microcentrifuge tubes each with a total volume of $50 \mu \mathrm{l}$, containing 10-25 ng of genomic DNA, 0.2 $\mathrm{mM}$ deoxynucleotide triphosphate (dNTP), $1.5 \mathrm{mM}$ magnesium chloride, $30 \mathrm{ng}$ primer and 2.5 unit of Taq DNA polymerase. Under the recommended buffer conditions, the PCR was performed for 40 cycles in a DNA thermal cycler (Perkin-Elmer Cetus, 480, USA) as follows: denaturation at $93^{\circ} \mathrm{C}$ for $20 \mathrm{~s}$, annealing at $50^{\circ} \mathrm{C}$ for $60 \mathrm{~s}$, extension at $72^{\circ} \mathrm{C}$ for $20 \mathrm{~s}$, followed by a final extension step at $72^{\circ} \mathrm{C}$ for 6 min. The amplification products were analysed by $4 \%$ Nuseive-Agarose gel electrophoresis run in Tris acetate buffer, and detected by staining with ethidium bromide and viewed on a UV transilluminator.

DRUG SUSCEPTIBILITY

Drug susceptibility tests were performed by the macrodilution method using yeast nitrogen base media. Four antifungal agents were used: amphotericin B (Squibb, Princeton, NJ), flucytosine (Hoffmann La Roche, Inc, Nutley, NJ), fluconazole (Pfizer, Sandwich, UK) and itraconazole (Janssen Pharmaceuticals, Piscataway, NJ). Final drug concentrations ranged from 32 to $0.015 \mu \mathrm{g} / \mathrm{ml}$ by two-fold serial dilution. The yeast cells were prepared from a 48 -h culture on SDA tubes incubated at $35^{\circ} \mathrm{C}$, then suspended in sterile $0.85 \%$ normal saline solution to obtain a final dilution of $1-5 \times 10^{5}$ cells $\mathrm{ml} ; 0.1 \mathrm{ml}$ was added to each tube. Minimum inhibitory concentrations (MIC) were read at 24 and $48 \mathrm{~h}$ using end-point criteria as defined by the National Committee for Clinical Laboratory Standards. ${ }^{10}$

\section{Results}

Isolates of $C$ neoformans were cultured from each of 87 patients ( 17 females, 70 males) with cryptococcal meningitis. The age ranges were: females $17-70$ years (mean 30.8, SD 13.8); males $14-60$ years (mean 32.4, SD 8.5). HIV infection was the underlying disease in all patients. Risk exposure for HIV infection was 
Table Sex, age, CD4 lymphocyte count, and duration of hospitalisation of cryptococcal meningitis patients with AIDS

\begin{tabular}{llll}
\hline & Females $(n=17)$ & Males $(n=70)$ & Total $(n=87)$ \\
\hline Age (years) & & & \\
$\quad$ range & $30.8 \pm 13.8$ & $32.4 \pm 8.5$ & $32.1 \pm 9.6$ \\
CD4 lymphocyte count $\left(/ \mathrm{mm}^{3}\right)$ & $17-70$ & $14-60$ & $14-70$ \\
$\begin{array}{c}\text { range } \\
\text { Length of hospitalisation (days) }\end{array}$ & $99-205$ & 41 & 45 \\
$\begin{array}{l}\text { patients who survived (range) } \\
\text { patients who died (range) }\end{array}$ & $23(14-31)$ & $4-212$ & $4-212$ \\
\hline
\end{tabular}

${ }^{\star}$ Values are mean $\pm \mathrm{SD}$

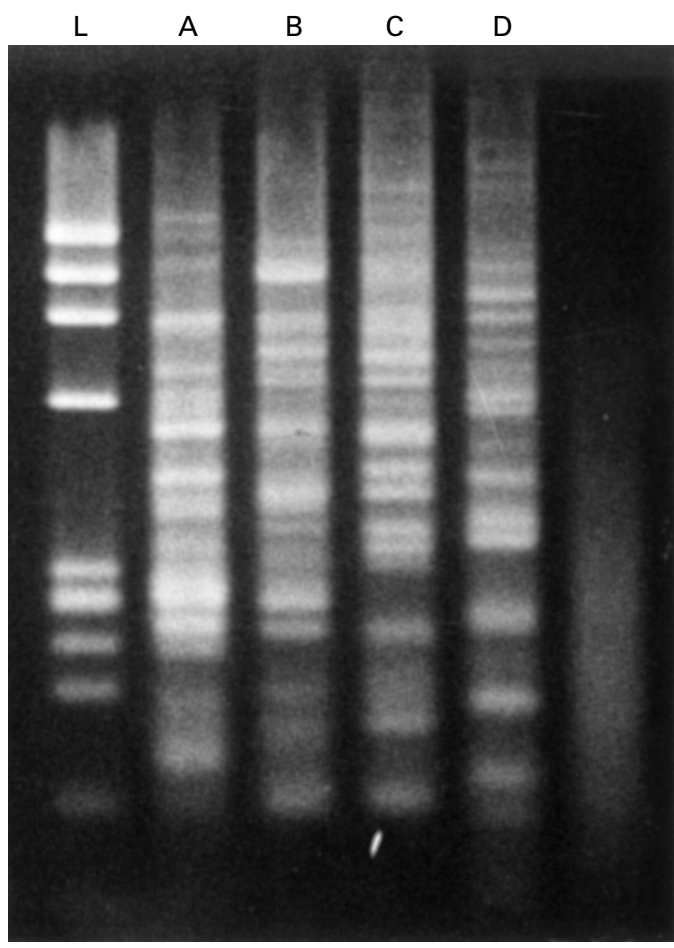

Figure 1 Electrophoretic separation of PCR fingerprints obtained after amplification of genomic DNA of four serotypes of $C$ neoformans with the phage M13 core sequence. $\mathrm{L}=\phi x \mathrm{DNA} / \mathrm{Hae}$ III DNA marker initial CSF latex agglutination test was 1:16 (range 1:4-1:128). After 3 weeks of treatment, CSF revealed no growth in $80 \%$ of patients, but the latex agglutination test for cryptococcal antigen titre remained positive.

Using culture as the gold standard, the sensitivities of the other methods for diagnosing cryptococcosis were: India ink preparation $91 \%$, latex agglutination $100 \%$, and PCR $86 \%$.

PCR fingerprinting with prototype strains of $C$ neoformans serotypes A, B, C, and D showed major diagnostic bands $15,13,17$, and 18, respectively (figure 1 ). There were 86 patients with serotype A and one patient with serotype B (figure 2). Moreover, additional strains of $C$ neoformans isolated from CSF, blood and urine from three patients and $C$ neoformans cultured from two patients under treatment each week for 3 weeks, revealed the same serotype A.

In addition to tuberculosis and other parasitic infectious complications in this group of patients, a 35-year-old woman also had histoplasmosis and two men ( 30 and 33 years old) had penicillosis marneffei. Only four patients suffered from optic neuropathy; all were males and PCR fingerprinting revealed serotype A. There were no skin lesions in these patients.

The mean MICs of amphotericin B, flucytosine, fluconazole and itraconazole against the 87 isolates of $C$ neoformans were $0.55 \mu \mathrm{g} / \mathrm{ml}$ $(0.25-1, \mathrm{SD}=0.22), 9.5 \mu \mathrm{g} / \mathrm{ml}(2-20, \mathrm{SD}=$ $4.91), 6.9 \mu \mathrm{g} / \mathrm{ml}(1-16, \mathrm{SD}=4.42)$ and 0.36 $\mu \mathrm{g} / \mathrm{ml}(0.125-1.0, \mathrm{SD}=0.23)$, respectively.

\section{Discussion}

From January 1996 to December 1997, 2643 129 patients attended the out-patient department and 119951 patients were admitted to Siriraj Hospital; this provided a large population in which to conduct this study. From a

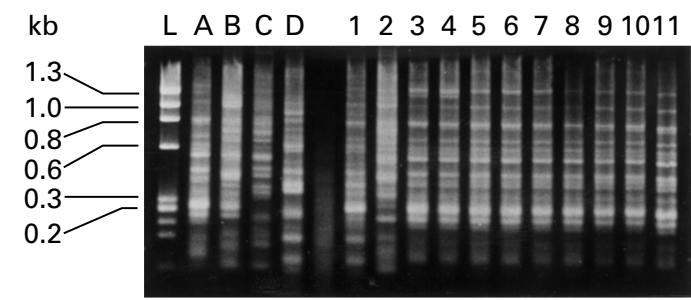

Figure 2 Electrophoretic separation of PCR fingerprints obtained after amplification of genomic DNA of four serotypes of $C$ neoformans and $C$ neoformans isolated from patients with the phage M13 core sequence. $\mathrm{L}=\phi \mathrm{xDNA} / \mathrm{Hae}$ III DNA marker

retrospective study at Siriraj Hospital before the AIDS era, the ratio of incidence of cryptococcosis in female:male patients was $2: 1$, cryptococcosis being a common infection in systemic lupus erythematosus. ${ }^{11-13}$ Nowadays it is regarded as a disease of sexually active people, primarily men with AIDS. The maleto-female ratio of the study patients was $4: 1$. This is in same range as the male-to-female ratio of HIV-infected patients in Thailand. In this study, the mean age of the patients was 32.1 years and mean CD4 lymphocyte count was $45 \mathrm{~mm}^{3}$. HIV infection occurs predominantly in the lower economic social class. This, together with the tendency of people to present to the hospital late, are the main reasons why many of the fatalities took place after a mean of only 14 days hospitalisation, which was shorter than the mean duration of admission of survivors (26 days, $\mathrm{p}<0.001$ ). The majority of patients died of increased intracranial pressure with severe headache, convulsion and coma. 
Some patients died of disseminated infection in lymph nodes, spleen and bone marrow.

The treatment of choice is amphotericin B $(0.5-0.8 \mathrm{mg} / \mathrm{kg} /$ day $)$. A combination of amphotericin B and flucytosine $(150 \mathrm{mg} / \mathrm{kg} /$ day $)$ is more effective than amphotericin $\mathrm{B}$ alone, but is associated with marrow suppression. Fluconazole (200-400 mg/day) can be used in patients whose signs and symptoms are not so severe and who can take medications orally. Secondary prophylaxis using amphotericin B $(1 \mathrm{mg} / \mathrm{kg})$ given intravenously every $1-2$ weeks or fluconazole $(100-200 \mathrm{mg} /$ day) taken orally is recommended to preventing recurrent infection.

Although PCR has been used in the diagnosis of various diseases, especially infectious diseases, it has only recently been introduced to diagnose cryptococcosis. However, its efficiency is not superior to that of India ink preparation or latex agglutination, the most commonly used conventional methods. Moreover, conventional methods are easy to perform and less expensive than PCR, which needs specific primers and experienced operators. ${ }^{14}$ The low titre of the latex agglutination test $(1: 16)$ in this study may be the result of early detection. In Thailand, where central nervous system fungal infection in HIVinfected patients is common, HIV-infected patients with neurological signs and symptoms are assessed promptly for cryptococcal infection.

In Papua New Guinea, in contrast to other countries, cryptococcal meningitis occurs predominantly in immunocompetent, previously healthy adults. $C$ neoformans var gattii was implicated in $95 \%$ of cases and ocular complications were common. ${ }^{15} \mathrm{~A}$ study in Italy

1 Rippon JW. Medical mycology. The pathogenic fungi and the pathogenic actinomycetes, 2 nd edn. Philadelphia: WB Saunders, 1982; pp 542-58.

2 Satitnimankarn T, Na Nakorn S, Rigunti M. Cryptococcosis, report of first case in Thailand. F Med Assoc Thai 1960, 43:78-80

3 Prariyachatigul C, Chaiprasert A, Meevootisom V, Pattanakitsakul S. Assessment of a PCR technique for the detection and identification of Cryptococcus neoformans. $7 \mathrm{Med}$ Vet Mycol 1996;34:251-8.

4 Kwon-Chung KJ, Bennett JE. Epidemiologic differences Kwon-Chung KJ, Bennett JE. Epidemiologic differences between the two varieties of

5 Salkin IF, Hurd NJ. New medium for differentiation of Cryptococcus neoformans serotype pairs. I Clin Microbiol 982;15:169-71.

6 Tanaka K, Kohno S, Miyazaki T. The eiken latex test for detection of a cryptococcal antigen in cryptococcosis. Mycopathologia 1994;127:131-4.

7 Meyer W, Mitchell TG, Freedman EZ, Vilgalys R. Hybridization probes for conventional DNA fingerprinting used as single primers in the polymerase chain reaction to distinguish strains of cryptococcus neoformans. $f$ Clin Microbiol 1993;31:2274-80.

8 Viviani MA, Wen H, Roverselli A, et al. Identification by polymerase chain reaction fingerprinting of Cryptococcus polymerase chain reaction fingerprinting of Cryptococcus

9 Beoformans serotype AD. J Med Vet Mycol 1997; 35:355-60. tion of fungal pathogens. In: Perrsing DH, Smith TF, Tenotion of fungal pathogens. In: Perrsing DH, Smith TF, Tenover FC, White TJ, eds. Diagnostic molecular microbiology.
Principles and applications. Washington, DC: American SociPrinciples and applications. Washington, DC
ety for Microbiology, 1993; pp 423-30.

10 National Committee for Clinical Laboratory Standards. Reference method for broth dilution antifungal susceptibility test ing for yeasts: proposed standard. Document M27-P. Villanova, PA: National Committee for Clinical Laboratory Standards, 1992

11 Leelarassami A, Danchaivichit S, Leelarassami I. Cryptococcosis : report of 19 cases from Siriraj Hospital. Bull Inf Dis Gr Thai $1982 \cdot 5 \cdot 52-62$.

\section{Summary points}

- cryptococcal meningitis in AIDS patients is a very common condition

- HIV in Thailand is more common in heterosexuals

- conventional methods (India ink preparation, latex agglutination test and culture) are reliable tests and the latex agglutination test is useful for monitoring patients

- Cryptococcus neoformans serotype A predominates (99\% of patients)

- in vitro susceptibility tests against the $C$ neoformans isolates showed them to be sensitive to the antifungals used

revealed that the incidence of serotype $\mathrm{D}$ was $71 \%$ and skin lesions were observed only in serotype $\mathrm{D}$ infections. ${ }^{16}$

As in our previous investigation ${ }^{17}$ and in that of Poonwan et al ${ }^{18}$ on serotypes of $C$ neoformans in Thailand, serotype A ( $C$ neoformans var neoformans) predominated in this study. This might explain why we had fewer problems with visual loss and skin lesions.

The susceptibility of $C$ neoformans to antifungal agents corresponded very well with the results of other studies and all isolates were sensitive to the antifungal agents tested. ${ }^{16-21}$

We would like to thank the representatives of Pfizer International Corp, Janssen Pharmaceuticals, Hoffman-La-Roche, and Bristol-Myers Squibb in Thailand for supplying fluconazole, itraconazole, flucytosine and amphotericin B, respectively. Dr Ira F Salkin (Albany, New York) provided strains of $C$ neoformans, Dr Shusee Visalyaputra analysed the data, and Dr Timothy Mastro, Dr Warren Brockelmann, and Dr Bob Cowan, reviewed the manuscript. This research work was supported by a grant from Mahidol University and partially supported by the Siriraj-Chalermprakiat Fund.

12 Imwidthaya P, Dithaprasop P. Egtasaeng C. Clinical and environmental isolates of Cryptococcus neoformans in Bangkok (Thailand). Mycopathologia 1989;108:65-7.

13 Imwidthaya P, Egtasaeng C. Latex agglutination test for diagnosing cryptococcosis. F Med Assoc Thai 1991;74:454-

14 Wu J, Liao W, Chai J. Isolation of specific DNA probes for detection of Cryptococcus neoformans. Mycoses 1997;40:385-

15 Seaton RA, Verma N, Naraqi S, Wembri JP, Warrell DA. Visual loss in immunocompetent patients with Cryptococcus neoformans var gattii meningitis. Trans $R$ Soc Trop Med Hyg 1997;91:44-9.

16 Tortorano AM, Viviani MA, Rigoni AL, Cogliati $M$, Roverselli A, Pagano A. Prevalence of serotype D in Cryptococcus neoformans isolates from HIV positive and HIVnegative patients in Italy. Mycoses 1997;40:297-302.

17 Imwidthaya P, Sethakorn C, Chaiprasert A, Sutthent R, Poungvarin N. Cryptococcus neoformans in Siriraj Hospital 1994-1995. Siriraj Hosp Gaz 1997;49:1145-52.

18 Poonwan N, Mikami Y, Poosuwan S, et al. Serotyping of Cryptococcus neoformans strains isolated from clinical specimens in Thailand and their susceptibility to various antifungal agents. Eur F Epidemiol 1997;13:335-40.

19 Anaissie E, Shawar R, Paetznick V, et al. Two-site comparison of broth microdilution and semisolid agar dilution methods for susceptibility testing of Cryptococus neoformans in three media. F Clin Microbiol 1993;31:1370-2.

20 Barchiesi F, Colombo AL, McGough DA, Rinaldi MG. Comparative study of broth macrodilution and microdilution techniques for in vitro antifungal susceptibility testing of yeast by using the national committee for clinical laboratory standards' proposed standard. F Clin Microbiol 1994;33 2494-500.

21 Ghannoum MA, Fu Y, Ibrahim AS, et al. In vitro determination of optimal antifungal combinations against Cryptococcus neoformans and Candida albicans. Antimicrob Agents Chemother 1995;39:2459-65. 